\title{
FINANCIAL PERFORMANCE FORECASTING OF THE ACTIVITY OF SMALL BUSINESS THROUGH APPLIED STATISTICS
}

\author{
Golibbek Rakhmonkulov ${ }^{\mathrm{a}}$, Wei Wang ${ }^{\mathrm{a},{ }^{*}}$ \\ ${ }^{a}$ School of Sciences, Zhejiang University of Science and Technology (ZUST), 310023, \\ Hangzhou, China \\ *Corresponding author: fannaoy@163.com
}

\begin{abstract}
In modern realities, in a market economy, it becomes important to analyze and forecast the main indicators of the financial activity of the enterprise. Financial management involves predicting the performance of the organization, since it allows you to perform a comprehensive analysis and assessment of the financial and economic prospects for the development of the organization, to formulate an optimal development strategy, as well as tactics of actions in the implementation of financial and supply chain activities. In addition, qualified economic specialists, thanks to knowledge of modern methods and technology for predicting the performance of an enterprise, are able to adapt in a timely manner to changes in the market situation in order to develop suitable solutions. The main objective of forecasting financial results for the next financial year is to assess the dynamics and analyze the relationship of indicators directly related to the financial condition of the enterprise, as well as having a significant impact on the formation of its financial result. Forecasting the financial results of the enterprise and analysis of its financial condition also allows you to identify problem areas that can lead to bankruptcy.
\end{abstract}

The article considers and analyze the main methods of forecasting the financial result of the organization.

Published by IJRP.ORG. Selection and/or peer-review under responsibility of International Journal of Research Publications (IJRP.ORG)

Keywords: Forecasting, Prognostics, Technical indicators, Bankruptcy, Models, Forecasting methods, financial result and efficiency.

\section{INTRODUCTION}

Today, one of the most important roles belongs to commercial organizations, since they are the most numerous and progressive form of business organization. It seems obvious that the activities of any commercial organization involve the investment of various kinds of funds (resources) and profit. In this regard, forecasting the financial result and the financial condition of the organization plays an important role, since it plays one of the key roles in making managerial decisions. Moreover, the forecast is also necessary for investors to evaluate profitability, possible risks, and to analyze the probability of a loan return. 


\section{MAIN PART}

In accordance with the definition most common in scientific publications, a prognostic - is a scientifically based assumption (foresight) about the possible state of an economic entity or the economic system as a whole in future periods. The prognostic is always based on certain information. In turn, the prognostic development process itself explain "forecasting". In essence, forecasting is a very effective tool for scientific foresight. As a rule, this tool is used mainly at the stage of formation of the plan. In this case, a multi-aspect variant analysis is carried out, the influence of various external and internal factors is evaluated, additional information is collected that underlies further decision-making. Among the main goals of financial forecasting are: identifying development alternatives; study of current farming trends; assessment of enterprise potential, etc.

Often, in practical activities, forecasting is carried out annually, since the financial results of the enterprise, in essence, are the main indicators of its effective and successful financial activity. Moreover, the principle of regularity allows us to compare the forecast values of indicators and their actual values. In addition, the annual conduct of a predictive study makes it possible to conduct an in-depth analysis of various conditions and factors that determine whether or not the actual value of the forecast indicators is achieved. As a rule, as a result of forecasting, relevant recommendations are formulated with the aim of improving the quality of forecasting, as well as to increase its effectiveness.

In general, we can distinguish the following stages of forecasting the economic process (phenomena)

1. Determination of the forecast period, sources of information, as well as possible forecasting methods. It should be noted that the forecasting period in each case is determined individually, since it depends on factors such as forecasting goals, the reliability of the data collected, etc.

2. Formulation of forecasting goals.

3. Determination of the most optimal forecasting method.

4. The formation of a set of reasonable indicators for each goal.

5. Gathering the necessary data, conducting their assessment

6. Directly developing a forecast.

7. Implementation of a multidimensional and integrated forecast analysis.

At the same time, it must be understood that if there are significant deviations in the forecasting process or if the information collected has serious distortions, the implementation of predictive calculations becomes meaningless. In addition, the future state of the environment should be taken into account. In modern conditions, one of the main tasks of forecasting is the determination of a situation specific to a region (country) and its comparison with the financial condition of the organization.

In addition, it is advisable, when making a forecast, as well as when assessing the possible dynamics of key indicators (such as, for example, prices of products sold), to provide several options, while using different initial information.

In this case, the calculation of the base scenario is the first option. The second option is to calculate an optimistic scenario.

In general, the following groups of methods for predicting the financial results of an organization can be distinguished:

- Methods of expert assessments. These methods are based on the expert assessment procedure, which is the process of obtaining an assessment of a problem (question) based on the opinions of specialists. In other words, a survey of qualified experts is conducted, a further analysis of the information received and the formulation of an appropriate decision. As a rule, in practice, the heads of the structural divisions of the company act as specialists, which allows us to make the most optimal and rational decision. Often, expert 

financial indicators;

- Deterministic methods. This group includes research methods in which the relationship between the considered parameters is determined (strictly defined). The main form of the financial result report is a tabular implementation of a rigidly determined factorial model, which traces the relationship of the effective attribute (net profit) and factors (revenue from sales, cost, other expenses, etc.);

- Stochastic methods assume the probabilistic nature of both the relationship between the forecast financial indicators and the source data, and the forecast itself. It should be noted that the research methods included in this group are the most significant in formalized forecasting. This is due to the fact that they allow you to significantly vary the applied algorithms in complexity. It is also necessary to mention that the use of statistical methods can lead to miscalculations and errors, since such methods are subject to the influence of arbitrary data fluctuations.

Many experts identify three main situations (groups) when using stochastic methods, the choice of which is based on a variety of heterogeneous criteria and factors (for example, the availability, reliability and completeness of the source information).

In practice, the first situation, as a rule, is quite common. So, a financial analyst (manager) as a basis for forecasting information on the dynamics of a particular indicator is used. In essence, this situation is the presence of a time series, i.e. a trend stands out. For this purpose, several methods can be used, among which the most common are analysis using autoregressive dependencies and dynamic analysis.

The second situation assumes the presence of a spatiotemporal aggregate. It occurs if:

1) The series of dynamics are insufficient in their length to form statistically significant forecasts.

2) In the forecasting process, it becomes necessary to take into account the influence of factors (conditions) that are different in dynamics and economic nature.

The following situation in practice is often encountered in the absence of any significant statistical data on the indicator due to the influence of various conditions (or if the value of the indicator is determined by a combination of factors). It consists in the presence of a spatial totality. In this case, multivariate regression analysis can be used, which is the extension of a simple dynamic analysis to the multidimensional case.

In modern conditions, one of the most relevant and important tasks for any enterprise is the timely diagnosis of the probability of bankruptcy. However, it must be understood that at the moment there are no techniques that allow us to predict the onset of bankruptcy with maximum reliability. In this regard, today specialists are developing many models necessary for predicting the risk of bankruptcy of an organization.

The most common bankruptcy forecasting models developed by E. Altman, a professor at the University of New York. There are two-, five- and seven-factor models, as well as a five-factor modified model. Models reflect the risk of future bankruptcy. In turn, the indicators that are used in the models allow us to evaluate the results of work for the reporting period and reflect the potential of the company as a whole. The simplest bankruptcy forecasting model is a two-factor model, based on two key indicators, on which, in accordance with Altman's opinion, the probability of bankruptcy depends: one of the indicators is the coverage ratio (this indicator is characterized by liquidity), the second indicator is the financial dependence ratio (in this the indicator reflects financial stability). The identification of the weight values of the coefficients occurs empirically.

A five-factor Altman model allows us to more accurately assess the risk of bankruptcy:

$$
\mathrm{Z}=1,2 * X 1+1,4 * X 2+3,3 * X 3+0,6 * X 4+X 5,(1)
$$

Where $\mathrm{X} 1$ = working capital to the total assets of the enterprise;

$\mathrm{X} 2$ - retained earnings to the total assets of the company;

$\mathrm{X} 3$ - profit before tax to the total value of assets;

$\mathrm{X} 4$ - market value of equity to the accounting (book) value of all liabilities;

X5 - total sales to total assets. 
However, it should be noted that in the Asian economy, the use of this model is difficult due to differences in accounting for a number of indicators, the absence of the impact of inflation on indicators, etc. In this regard, domestic experts are developing models that can be used in Asia.

Therefore, at the Tashkent State University of statistics based on research on statistical materials from fifty printing companies, a two-factor model was derived:

Where $\mathrm{q}^{\mathrm{tl}}$ is the total coverage ratio;

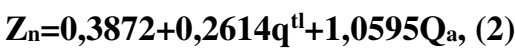

$\mathrm{Q}_{\mathrm{a}}$ - autonomy coefficient $\left(\mathrm{Q}_{\mathrm{a}}=1-\mathrm{K}_{2}\right.$, where $\mathrm{K}_{2}$ - according to the formula $\left.\mathrm{Z}_{\mathrm{A} 2}\right)$.

The probability of bankruptcy directly depends on the indicator $Z_{\mathrm{n}}$ :

- $Z_{\mathrm{n}}<1,3257$ - means the maximum probability of bankruptcy;

- $Z_{\mathrm{n}}$ is located in the interval between 1.3257 and 1.5475 - which means that the probability of bankruptcy is increased;

- $Z_{\mathrm{n}}$ is located in the interval between 1.5745 and 1.7693 - which means the probability of bankruptcy is at an average level;

- $Z_{\mathrm{n}}$ is located between 1,7693 and 1,9911 - it means the probability of bankruptcy is low;

- For $Z_{\mathrm{n}}>1.9911$ - means the probability of bankruptcy is minimal.

During the development of any forecasting model, it is assumed that the future situation will not undergo significant changes in comparison with the current one. Nevertheless, the model is nothing more than a kind of coarsening of the real situation by selecting a limited number of factors (indicators) from the set of existing ones. In this regard, the efficiency and accuracy of the model, as well as the result obtained, will depend primarily on the validity of this selection.

The figure number and caption should be typed below the illustration in $8 \mathrm{pt}$ and left justified. For more guidelines and information to help you submit high quality artwork please visit: http://ijrp.org/page/instruction. Artwork has no text along the side of it in the main body of the text. However, if two images fit next to each other, these may be placed next to each other to save space, see Fig 1 . They must be numbered consecutively, all figures, and all tables respectively.

\section{CONCLUSION}

Forecasting the results of the financial and economic activities of the enterprise is one of the key goals of a prospective economic analysis. The basis for the successful achievement of this goal lies primarily in the analytical study of the enterprise as a multi-aspect and diverse economic system, which, in turn, is characterized by many interconnected processes and the influence of a large number of factors and conditions. Forecasting plays an important role in the development of promising areas of activity, since it is one of the aspects of successful enterprise management. In essence, forecasting links the stages of planning and control, while forming a holistic process. Thus, from the effective forecasting of the financial results of the enterprise depends largely on its success.

\section{REFERENCES}

1. Ouhatlant I. A. (2019) profit Management: Benefit. - M.: Omega-L, 304 p.

2. Musaeva I. L., Margolava T. O. (2018) Analysis of problems of planning and forecasting of indicators of activity of the enterprise. Socio-economic phenomena and processes. №1. - Pp. 65-72.

3. Somiloon B. B. Article: "Methods of forecasting financial results". [Electronic source.]: https://cyberleninka.ru/article/n/metodyprognozirovaniya-finansovyh-rezultatov (date accessed 09.12.18).

4. Ltipin F. M., Somelova T. V. Modern models of forecasting financial results. Young scientist. — 2016. — №10. — P. 875-878. [Electronic source.]: https://moluch.ru/archive/114/30181/ (accessed: 09.12.2018).

5. Article: "Methodical bases of definition of probability of bankruptcy of subjects of managing". [Electronic source.]: https://buklib.net/books/30760/ (accessed: 09.12.2018). 
6. Iosif R. A. Article: "Forecasting financial results in the management system of the enterprise." [Electronic source.]: ${ }^{\text {Iss: }: 2708-3578 \text { (online) }}$ https://elibrary.ru/item.asp?id=23466713 (date accessed: 09.12.2018)

7. Omehina O. E. Modern problems of predicting bankruptcy of enterprises // Bulletin of the Volga University. V. N. Tatishcheva. - 2017. - №1. - P. 75-81.

8. Tahenkava S. V. (2015) Model of Altman as a way to assess the solvency of an enterprise // journal of science and education. №4 (6). - Pp. 134-137.

9. Loorin I. A. (2018) five-factor model of Altman. Forecasting risk of bankruptcy of the enterprise // Science among us. №1 (5). - P. 355-359.

10. Tillaev I. T. (2016) the Analysis of the financial condition and financial results of business entities. - M.: InfraM, 214 p. 
